\title{
Análise da dimensão espacial da pobreza em Minas Gerais
}

\author{
Nara Lívia de França Morais \\ Graduanda em Ciências Econômicas pela Universidade Federal de Uberlândia \\ Pesquisadora bolsista do Programa de Educação Tutorial (PET) \\ E-mail: naraliviamorais@gmail.com
}

\section{Julio Fernando Costa Santos}

Doutor em Economia pela Universidade Federal de Uberlândia

Professor Adjunto da Universidade Federal de Uberlândia

E-mail: julio.costa@ufu.br

Resumo: Dadas as disparidades regionais que caracterizam o estado de Minas Gerais, torna-se cada vez mais relevante investigar o comportamento da taxa de pobreza e a forma como os municípios pobres se distribuem no estado. Nesse sentido, o objetivo desse trabalho é investigar a distribuição espacial da pobreza no estado de Minas Gerais. Para isso, utilizou-se do método econométrico espacial para averiguar a presença de autocorrelação espacial. A partir da análise exploratória dos dados foi possível constatar a presença de dependência espacial entre as variáveis e a formação de clusters de pobreza. Por meio da regressão estimada pelo Método das Defasagens Espaciais foi possível ratificar a presença de dependência espacial, confirmada pela relevância da variável pobreza na vizinhança (variável pobreza defasada) no modelo. Portanto, conclui-se que a pobreza de um município é explicada, em parte, pela pobreza de seus municípios vizinhos.

Palavras-chave: Econometria espacial, Pobreza, Minas Gerais.

Abstract: Considering regional disparities that characterize Minas Gerais, it is becoming increasingly relevant to investigate the behavior of the poverty rate and the spatial distribution of poverty in municipal level. In this sense, the objective of this work is to investigate the spatial distribution of poverty in the state of Minas Gerais. For this, the instrumental of Spatial Econometrics was used to verify the presence of spatial autocorrelation. From Exploratory Spatial Data Analysis of the data it was possible to verify the presence of spatial dependence between the variables and the formation of poverty clusters. Through the regression estimated by the Space Lag Method, it was possible to ratify the presence of spatial dependence, confirmed by the relevance of the neighborhood poverty variable (spatial lag) in the model. Therefore, it is concluded that the poverty of a municipality is partly explained by the poverty of its neighboring municipalities.

Key words: Poverty, Spacial Analysis, Minas Gerais.

JEL Code: C49, 132 


\section{INTRODUÇÃO}

Apesar das taxas de pobreza terem se reduzido, o Brasil ainda apresenta um dos piores indicadores de pobreza e desigualdade de renda da América Latina (RIBEIRO; ARAUJO; FEITOSA, 2015). Segundo dados do Censo 2010, 55\% dos municípios brasileiros e 58\% dos municípios mineiros têm renda per capita média menor do que o salário mínimo vigente a época, $\mathrm{R} \$ 510$. Quanto a Minas Gerais, a maior parte desses municípios encontra-se nas mesorregiões do Norte de Minas e Vale do Jequitinhonha, o que atesta a distribuição desigual dos municípios pobres no estado. Nesse sentido, mostra-se cada vez mais necessárias análises que não consideram a pobreza apenas pelo aspecto da renda, mas levam em consideração outros aspectos mais amplos, como a distribuição dos municípios pobres em um dado estado.

A pobreza pode ser analisada por duas perspectivas: unidimensional e multidimensional. Pelo viés unidimensional, considera-se pobres todos aqueles que tem renda menor do que um valor estabelecido. Para tanto, define-se uma linha de pobreza monetária e todos são classificados segundo esse parâmetro. Pelo viés multidimensional, por outra via, considera-se pobre o indivíduo que não tem um nível de renda mínimo, mas não só. Nessa abordagem, é levada em consideração o acesso dos indivíduos a bens e serviços ditos essenciais, tais como acesso a saúde, educação e habitação de qualidade. Varia, nesse caso, o que cada autor considera como os elementos que caracterizam a pobreza (KAGEYAMA; HOFFMANN, 2006).

Atualmente, tem-se consolidado análises baseadas em Amartya Sen e Matha Nussbaum, que consideram o aspecto multidimensional a fim de propiciar visualizações mais amplas da pobreza. Isso porque a compressão das dimensões da pobreza é complexa e, dessa forma, considerar que a pobreza está apenas associada a renda não permite que todas as nuances do problema sejam vislumbradas. Quanto à localização dos municípios pobres, destacam-se alguns trabalhos ainda pouco conhecidos de distribuição espacial da pobreza, como os esforços feitos por Avila (2013), Silva, Borges e Parré (2014) e Leite (2016). Estes, por sua vez, consideram que a pobreza de um município está relacionada ao local onde esse município está situado e aos seus vizinhos, de forma que estar próximo a um município pobre interfere em suas condições.

Embora se reconheça nos trabalhos que consideram a pobreza multidimensional um avanço no entendimento dos determinantes e das características da pobreza, outras análises, que podem ser complementares, também se fazem úteis. Nesse sentido, esse artigo pretende investigar a distribuição espacial da pobreza em Minas Gerais, de forma averiguar se a pobreza de um município interfere na pobreza de seus vizinhos e em que medida elas se relacionam com outras características socioeconômicas internas.

Dessa maneira, a principal contribuição desse trabalho consiste na estimação de modelos econométrico espaciais. Tal metodologia, associada ao cálculo do Índice de Moran e da análise da formação de clusters de pobreza, permite a investigação da presença de dependência espacial e da avaliação ceteris paribus, por meio da análise da regressão, da relação entre vizinhos para a determinação da pobreza de um município.

Além dessa introdução, esse artigo se subdivide em cinco seções. A primeira delas tem por objetivo revisitar a literatura e a analisar as formas distintas de mensuração do que é pobreza; a segunda busca analisar a situação e a evolução da pobreza no Brasil e no Estado de Minas Gerais; a terceira detalha a metodologia utilizada; a quarta seção 
apresenta os resultados das análises econométricas; e, por fim, a quinta seção sintetiza as discussões apresentadas nesse artigo.

\section{O QUE É POBREZA?}

A pobreza pode ser analisada por meio de várias perspectivas e é em razão disso que não há um conceito unânime. A partir de alguns estudos e a implementação de políticas de combate à pobreza, percebeu-se que a renda não era o único caráter que definia um indivíduo como pobre. Portanto, inicialmente prevaleciam as análises unidimensionais que consideram a renda como critério principal para classificar um indivíduo como pobre; com o aprimoramento das avaliações, essa visão passa a ser complementada por análises mais completas e complexas em que mais variáveis eram consideradas (SANTOS; CARVALHO; BARRETO, 2017).

Dentre as abordagens que consideram principalmente o aspecto qualitativo, Yasbek (2005) se destaca por tratar a temática pelo viés político e social. A situação de pobreza e miséria, segundo essa autora, é oriunda do sistema capitalista que intrinsicamente impõe uma situação de desigualdade econômica, social, política e cultural. Sua análise pressupõe que no próprio desenvolvimento do sistema capitalista há uma diferenciação explicita entre pobres e não pobres. E é esse um dos motivos para que a pobreza não possa ser enxergada apenas pelo viés da renda, segundo a autora, mas sim agregando outros aspectos que culminem numa abordagem multidimensional.

Segundo Barros, Henriques e Mendonça (2000) a pobreza pode ser caracterizada como a situação em que o indivíduo carece de um padrão de mínimo de vida que lhe garanta a satisfação de suas necessidades básicas. Essas necessidades, todavia, seriam definidas de acordo com o momento histórico e a situação do país analisado. Dessa maneira, a pobreza pode ser entendida como qualquer tipo de privação, seja ela de ordem cultural, social ou econômica, que coloque alguns indivíduos em situação desigual frente a todos os outros em uma dada sociedade (KAGEYAMA; HOFFMANN, 2006).

Nesse sentido, pode-se generalizar o conceito de pobreza reduzindo-a as necessidades básicas não satisfeitas, o que quer dizer que existem pessoas "que não têm acesso a uma série de bens e serviços considerados como mínimos para uma vida de qualidade" (CAON; MAGALHÃES; MOREIRA, 2012, p.30). Porém, de forma mais completa, associando os conceitos uni e multidimensionais de pobreza pode-se, por fim, definir a pobreza não apenas como o acesso restrito a bens materiais e imateriais, mas sim como uma carência generalizada personificada na privação do acesso de bens e serviços essenciais para a sobrevivência.

\section{A SITUAÇÃO DO BRASIL E DE MINAS GERAIS}

Assim, nesse trabalho, busca-se analisar os níveis de pobreza no estado de Minas Gerais de forma a associar os aspectos multidimensionais à análise da renda, com ênfase nos aspectos ligados a dispersão territorial da pobreza no dado estado. Segundo Avila e Bagolin (2013), a análise espacial da pobreza está relacionada a possibilidade de concentração da população pobre em uma dada região. Todavia, antes de tratar especificamente dos desdobramentos de uma análise espacial da pobreza, cabe especificar o caso brasileiro e o caso mineiro, foco principal desse trabalho. 
No que diz respeito aos estudos sobre pobreza no Brasil é consensual o fato de que a pobreza no país está principalmente associada à desigualdade. Fahel, Teles e Caminhas (2016) apontam que o Brasil não é um país pobre, mas por enfrentar extrema desigualdade é negado a parte da população o acesso a condições mínimas de sobrevivência enquanto a outra parte da população é destinada a maior parte da riqueza. Para Barros, Henriques e Mendonça (2000, p.123) "o Brasil não é um país pobre, mas com muito pobres".

Se analisada a perspectiva histórica, a pobreza no Brasil tem origem em seu passado colonial. Os grandes latifúndios e o padrão de concentração de renda que serviram para manter o modelo agrário exportador primário foram também responsáveis pelas características de desigual distribuição de renda no país que perduram até o presente (SIMÃO, 2004).

Segundo Barros, Henriques e Mendonça (2000), a pobreza pode ser associada a dois aspectos principais: escassez de recursos e a má distribuição destes. Nesse sentido, concluem que a pobreza no Brasil não pode ser unicamente explicada pela escassez de recursos, mas principalmente pela desigualdade de distribuição destes. Como evidenciado pelos autores, o cerne do problema brasileiro com a pobreza está na desigualdade. Isso porque desde o princípio a distribuição de riquezas nesse território se deu de forma que parte da população não tem acesso ao mínimo para sobreviver enquanto outra parte goza de grandes riquezas.

Assim, para entender a pobreza no Brasil é necessário também compreender os fatores que intensificam e justificam essa má distribuição da renda. De acordo com Rached (2010, p.17:

A persistência da distribuição desigual de renda no país reflete e sintetiza a gravidade de diversos problemas nacionais, como a informalização crescente do mercado de trabalho, a questão agrária, a política do salário mínimo, os déficits de oferta de serviços públicos básicos, a desigualdade entre pessoas e os desequilíbrios regionais.

Logo, essas desigualdades características ao Brasil não se restringem apenas as relações entre os estados, mas são perceptíveis também na dinâmica interna dos estados brasileiros (SIMÃO, 2004). De acordo com Alves e Fontes (2001), análises sobre pobreza no estado confirmam uma desigual distribuição da riqueza, culminando na presença de desigualdades inter-regionais. Assim, dado o objetivo desse trabalho de analisar a pobreza especificamente no estado de Minas Gerais, cabe uma análise do estado no que tange a esse aspecto.

O estado de Minas Gerais é um dos 27 estados federativos do Brasil e pertence a região Sudeste do país juntamente com os estados do Rio de Janeiro, São Paulo e Espírito Santo. Tem área total de $586.528 \mathrm{~km}^{2}, 7 \%$ do território nacional e, segundo o Censo 2010 , população total de aproximadamente 19 milhões; sendo que 85,3\% estão localizados na área urbana e 14,7\% na área rural. Além disso, o estado é composto por 853 municípios, 12 mesorregiões e 10 regiões de planejamento.

A respeito da dinâmica econômica do estado, Silva, Fontes e Alves (2006, p.75) destacam que: 
A desigualdade regional de renda é uma característica presente no estado de Minas Gerais, que também apresenta grande heterogeneidade no que diz respeito às suas características geográficas, econômicas e sociais. Tal estado apresenta uma economia dual e uma dinâmica de desigualdade que precisa ser quebrada.

Essas desigualdades presentes no estado de Minas Gerais, tal qual a situação no Brasil, podem ser explicadas em razão de um contexto histórico. No caso mineiro, as regiões mais dinâmicas são aquelas em que historicamente houve maior sucesso nas lavouras cafeeiras culminando em maior acumulação de capital, no desenvolvimento capitalista e industrial. É também notável a importância para o estado a proximidade geográfica com o estado de São Paulo, sendo as cidades mais próximas aquelas que mais se desenvolveram (PEREIRA; HESPANHOL; 2015).

Segundo Santos e Pales (2012), as diferenças entre as principais regiões mineiras não são apenas quanto ao grau de desenvolvimento, mas também quanto ao acesso a renda, a saneamento básico, a saúde e a educação. Além disso, Fontes e Alves (2001) apontam que o estado é bastante heterogêneo tanto no que diz respeito a questão econômica quanto geográfica e social. A explicação para isso vem tanto da sua grande extensão territorial quanto do fato de que historicamente a renda foi dividida de forma desigual.

A despeito dessas disparidades entre as regiões mineiras, Caon, Magalhães e Moreira (2012, p.25) apontam que:

Pobreza e indigência se manifestam de maneira bastante diversa entre as Regiões de Planejamento do Estado. As Regiões de Planejamento Jequitinhonha/Mucuri e Norte se destacam com maiores percentuais de domicílios pobres e indigentes, muito acima da média estadual e de outras regiões como Triângulo, Centro Oeste, Alto Paranaíba e Central.

O estado de Minas Gerais, dessa maneira, assim como está destacado na figura 1, se divide em duas grandes regiões: o Norte, com menor renda, e o Sul, com maior renda. Como evidenciado na figura acima, os municípios que pertencem as regiões do Triângulo Mineiro e Alto Paranaíba têm renda média mais alta e as regiões ao norte e ao nordeste do estado, pelo contrário, tem níveis de renda média mais baixos.

Portanto, a pobreza e a sua dispersão no território brasileiro são desiguais, característica esta que não se limita à dinâmica entre os estados brasileiros e que é também observada nas relações inter-regionais. Cientes disto, destaca-se a importância do método da econometria espacial para averiguar a importância da localização de um município para definição de que esse é ou não um município pobre (SANTOS et al., 2014).

Segundo Chiarini (2008, p.78):

O instrumental econométrico espacial é capaz de descrever e visualizar as distribuições geográficas da pobreza e das demais 
variáveis, identificando localizações atípicas, descobrindo formas de associação (ou seja, se a pobreza nos municípios cearenses se distribui de forma aleatória ou se existe evidência de algum tipo de dependência espacial entre as medidas) que, por sua vez, podem ser de caráter global ou local e sugerindo estruturas no espaço geográfico.

Figura 1: Distribuição dos municípios segundo renda média per capita em 2010

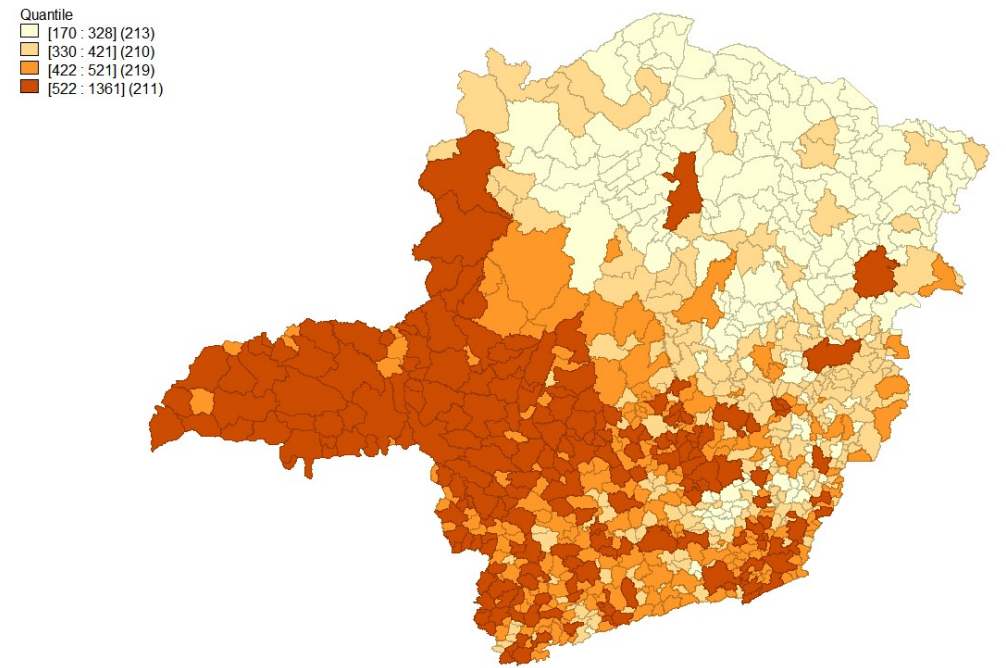

Fonte: Elaboração própria a partir de dados do Censo (2010) disponibilizados pelo IBGE.

Assim, no que tange ao objetivo de analisar a pobreza a partir da ótica da econometria espacial, alguns trabalhos se destacam, tais como: Avila e Bagolin (2013), Chiarini (2008) e Santos, Carvalho e Barreto (2017).

Avila e Bagolin (2013) analisaram, a partir do instrumental da econometria espacial, a distribuição da pobreza no estado do Rio Grande do Sul. Para tanto, utilizaramse do tratamento uni e multidimensional da pobreza. Como resultado, encontraram a presença de cluster de pobreza no estado, de forma que utilizando uma análise multidimensional o número de clusters encontrados foi maior do que numa análise unidimensional. Tal evidência é um indício de que políticas públicas voltadas apenas para a pobreza como carência de renda não são suficientes.

Chiarini (2008) fez uma análise espacial da pobreza no estado do Ceará no período de 1991 a 2000. A partir das análises feitas confirmou que há a formação de clusters de pobreza no Ceará com a presença de processos de difusão de contágio. O autor salienta que as análises feitas e o resultado encontrado devem servir de base para a formulação de políticas públicas, dado que fornecem um melhor direcionamento das localidades mais afligidas com a miséria.

Santos, Carvalho e Barreto (2017) fizeram uma análise espacial da pobreza no estado da Bahia utilizando variáveis multidimensionais como educação, saúde e habitação associados a análise de renda. Tiveram como resultado a confirmação da presença de clusters de pobreza no estado da Bahia. As análises foram feitas com dados dos anos de 2000 e 2010 a partir da criação de índices de pobreza comparáveis aos índices já existentes. 
Portanto, dadas as características de distribuição desigual da pobreza nos municípios mineiros, de forma que se percebe que algumas regiões são caracterizadas pela predominância de municípios pobres, o objetivo desse trabalho é o de, a partir do instrumental da econometria espacial, analisar a incidência de pobreza nos municípios mineiros e a sua distribuição espacial, de maneira a identificar a relação entre municípios pobres e a sua distribuição no espaço.

\section{METODOLOGIA}

\subsection{Dados utilizados}

Dado o objetivo de analisar a pobreza em Minas Gerais a partir do instrumental da econometria espacial, foram utilizados dados que contemplem a análise tanto pelo viés da renda quanto pelo viés da restrição ao acesso a certos serviços. Nesse sentido, como o intuito é avaliar a distribuição espacial dos indicadores de pobreza, foram utilizados também os dados georreferenciados (shapefile) dos municípios do estado de Minas Gerais divulgados pelo IBGE. Já a base de indicadores utilizadas para a discussão sobre pobreza são dados municipais do Censo 2010. Os indicadores utilizados são:

i. Pobreza: razão dos moradores em domicílios particulares com rendimento mensal per capita até o limite do bolsa família sobre o total de moradores em domicílios particulares. Em agosto de 2010, esse valor era de $\mathrm{R} \$ 140,00$.

ii. Renda Média Domiciliar per Capita: Média das rendas domiciliares per capita das pessoas residentes no município. A renda domiciliar per capita é a soma dos rendimentos mensais dos moradores do domicílio pelo número de moradores.

iii. Grau de Urbanização: percentual da população da área urbana sobre a população total.

iv. Índice de Gini da Renda Domiciliar per capita. Mede o grau de concentração da distribuição de renda domiciliar per capita de uma determinada população em um município. O valor zero mede a situação de igualdade, ou seja, todos tem a mesma renda e o valor um mede a total desigualdade, ou seja, uma pessoa tem toda a renda.

\subsection{Análise exploratória dos dados (AEDE)}

Nesse momento, o objetivo é avaliar se existe dependência espacial entre as variáveis apresentadas, ou seja, se dada variável influencia a mesma variável em uma localidade geograficamente próxima. Para isso utiliza-se AEDE para encontrar padrões entre a distribuição das variáveis pelo estado. O método utilizado, da análise da dependência espacial, também permite a detecção de outliers e de formação de clusters, elementos importantes para análise que se propõe nesse artigo.

Conforme Almeida (2012 apud AVILA; BAGOLIN, 2013), é preciso, para que se possa fazer as análises de dependência espacial, definir a matriz $W$ de pesos espaciais. Essa é uma matriz quadrada de ordem $n$ em que seus elementos, wij, indicam qual o grau de interação entre duas regiões. Espera-se que para uma dada variável conforme dois municípios se distanciem, eles carreguem menos características semelhantes, ao passo que municípios vizinhos são influenciados uns pelos outros. 
p. 45 - Análise da dimensão espacial da pobreza em Minas Gerais

Nesse sentido, essa matriz é montada de forma que se dois municípios são vizinhos, a relação de vizinhança entre o município i e o município j assume o valor 1 $(w i j=1)$ e se os dois municípios não são vizinhos, a relação de vizinhança entre o município i e o município j assume o valor $0(w i j=0)$

\section{3. Índice Global de Moran}

Parte-se do Índice de Moran para averiguar se a dependência espacial está presente no banco de dados analisado. Mais especificamente, o índice de Moran busca testar a sua hipótese nula de que os dados estão distribuídos aleatoriamente. A estatística pode variar de -1 a 1 . Para valores negativos, indica correlação negativa, ou seja, que altos valores de uma variável estão próximos a baixos valores dessa mesma variável; para valores positivos, indica correlação positiva, ou seja, altos valores próximos a altos valores. Se for zero, não há dependência espacial entre as variáveis. (ALMEIDA, 2012).

Segundo Santos, Carvalho e Barreto (2017), a fórmula do Índice Global de Moran é dada por:

$$
I_{t}=\left(\frac{\left(y_{i}-y\right) \sum_{j} w_{i j}\left(y_{j}-y\right)}{\sum_{i}\left(y_{i}-y\right)^{2 / n}}\right)
$$

Em que wij é o valor da matriz de vizinhança para a região $i$ com a região $j$ em função da distância $d$, e $y i$ e $y j$ são os desvios em relação à média.

Gráfico 1- Gráfico de dispersão do Índice de Moran

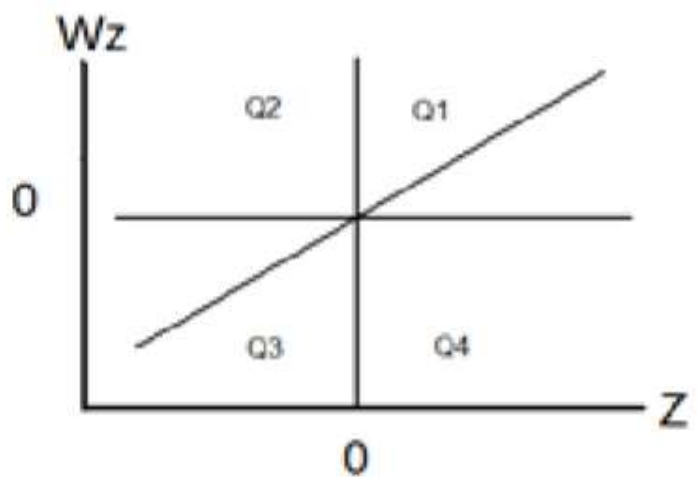

Fonte: Silva, Borges e Parré (2014)

Assim, como apresentação no gráfico 1, o Índice de Moran também pode ser analisado graficamente. O primeiro quadrante (Q1) evidencia situações alto-alto, ou seja, regiões em que os vizinhos carregam altos valores para a variável em questão. O segundo quadrante (Q2) evidencia situações baixo-alto, ou seja, municípios com baixos valores para a variável em questão próximos a municípios com altos valores para a variável em questão. O terceiro quadrante (Q3) evidencia regiões baixo-baixo em que municípios com baixos valores para a variável em questão estão próximos a municípios que assumem também baixos valores para as variáveis em questão. O quarto quadrante (Q4) evidencia situações alto-baixo, ou seja, regiões em que municípios que assumem altos valores para 
a variável em questão estão próximos aos municípios que assumem baixos valores para a mesma variável.

Em Q1 e Q3 há autocorrelação positiva e a formação de clusters, ou seja, agrupamento de municípios que assumem o mesmo comportamento para a dada variável. Em Q2 e Q4 há autocorrelação negativa e a detecção de outliers, aqueles municípios cujo comportamento é diferente dos seus vizinhos.

\subsection{Modelos econométricos}

Depois de averiguar a existência de autocorrelação espacial entre as variáveis (LISA) e calcular o Índice de Moran, se comprovada a dependência espacial das variáveis, faz-se necessário calcular os modelos econométricos espaciais. Esses modelos se diferem dos modelos tradicionais por apresentarem um componente espacial. A depender do modelo escolhido esse componente pode ser a defasagem na variável dependente, a defasagem na variável dependente e/ou a defasagem no termo de erro.

Cabe salientar que o modelo tradicional não é suficiente para a análise que se pretende fazer nesse momento. Isso porque em razão da presença de autocorrelação espacial os resultados encontrados serão pouco eficientes (quando a correlação ocorre no termo de erro) ou serão viesados e inconsistentes (quando a correlação ocorre entre as variáveis independentes).

Nesse sentido, existem dois modelos econométricos espaciais principais que podem ser utilizados:

i) Modelo por defasagem espacial

O modelo é dado por:

$$
Y=\rho W y+X \beta+\varepsilon
$$

Em que $\rho W y$ é a variável dependente defasada pela matriz de pesos espaciais, $X$ representa uma matriz com as variáveis explicativas, $\rho$ e $\beta$ são parâmetros e $\varepsilon$ é o erro do modelo normalmente distribuído.

ii) Modelo por erro espacial

O modelo é dado por:

$$
Y=\beta_{1}+\beta_{2}+\mu
$$

Em que $\mu=\lambda W \mu+\varepsilon$. O termo $\lambda W \mu$ representa $\circ \mu$ defasado pela matriz de pesos espaciais.

iii) Modelo estimado O modelo a ser estimado, considerando as variáveis já apresentadas, é dado por:

Pobreza $=\beta_{1}+\beta_{2}$ Renda média $+\beta_{3}$ Urbanização $+\beta_{4}$ Gini $+\varepsilon$ (3)

Segundo Vieira (2009), pode-se utilizar qualquer um desses dois modelos para estimar o modelo definido e a escolha de qual modelo é o mais adequado se dá por meio de alguns testes. Primeiro, deve se estimar o modelo por meio do Método dos Mínimos Quadrados (MQO) e testar a hipótese de que existe dependência espacial por meio dos testes dos Multiplicadores de Lagrange $(M L \rho$ e $M L \lambda)$. Se os dois testes forem 
p. 47 - Análise da dimensão espacial da pobreza em Minas Gerais

estatisticamente significantes, deve-se proceder na análise a fim de se definir qual dos dois é mais significativo. Para tanto, calcula-se os Multiplicadores de Lagrange robustos $(M L * \rho$ e $M L * \lambda)$. Aquele que for mais significativo deve ser o modelo utilizado.

\section{RESULTADOS ENCONTRADOS}

\subsection{Estatística descritiva}

Antes de iniciar as análises econométricas, é importante avaliar algumas características gerais da amostra que se pretende analisar.

Tabela 1 - Descrição das variáveis

\begin{tabular}{llll} 
Variáveis & Média & Mínimo & Máximo \\
\hline Pobreza (\%) & 17,63 & 11,72 & 57,66 \\
Renda média (R\$) & 435,91 & 170 & 1361 \\
Grau de urbanização (\%) & 67,92 & 18,56 & 100 \\
Índice de Gini & 0,473 & 0,32 & 0,78 \\
\hline
\end{tabular}

Fonte: Elaboração própria

Nesse sentido, apreende-se na tabela 1 que em Minas Gerais, no ano de 2010, em média: $17,63 \%$ da população vivia com menos de $\mathrm{R} \$ 140,00$; a renda média era de $\mathrm{R} \$ 435,91 ; 67,92 \%$ vivia em áreas urbanas e o índice de Gini era de 0,473. Acrescenta-se a isso o fato de que os valores mínimos de pobreza e grau de urbanização ainda são elevados e tem valores máximos que em muito ultrapassam a média. Ou seja, essa análise preliminar já dá indícios de que essas variáveis precisam ser melhor analisadas.

\subsection{Econometria espacial}

\subsection{1. Índice de Moran Global}

No caso desse trabalho, dado o objetivo de investigar a dependência espacial de variáveis relacionadas a pobreza, espera-se encontrar uma correlação positiva em que municípios pobres estão próximos a municípios também pobres.

Tabela 2 - Índice de Moran das variáveis analisadas

\begin{tabular}{lll} 
Variável & Índice de Moran univariado & Índice de Moran bivariado \\
\hline Pobreza & 0,776 & \\
Renda média & 0,619 & $-0,657$ \\
Grau de urbanização & 0,382 & $-0,428$ \\
Índice de Gini & 0,133 & 0,278 \\
\hline
\end{tabular}

Fonte: Elaboração própria.

Como evidenciado na tabela 2, os índices de Moran univariados calculados para as variáveis pobreza, renda média, grau de urbanização e índice de Gini indicam que todas essas variáveis não têm distribuição aleatória, ou seja, são espacialmente 
dependentes. Apesar de todos os índices calculados indicarem a presença de dependência espacial, percebe-se que para as variáveis pobreza e renda média esse aspecto é mais evidente $(I>0,6)$. Isso indica que essas variáveis são mais explicadas pela localização do que por fatores internos ao município.

Quanto ao índice de Moran bivariado, em que se analisa as variáveis renda média, grau de urbanização e índice de Gini frente a pobreza, percebe-se o mesmo: todas as variáveis são espacialmente dependentes a pobreza. Todos esses são indícios de que a pobreza de um município pode ser explicada não só por aspectos específicos e internos a esse município, mas também por sua localização geográfica. Cabe destacar que nos dois casos o índice de Gini apresenta menor Índice de Moran, o que indica baixa dependência espacial.

\subsubsection{Análise da dependência espacial (LISA)}

Para investigar a dependência espacial entre duas variáveis, pode-se utilizar também a análise da dependência espacial local (LISA). Por meio desse instrumento é possível averiguar a formação de clusters de pobreza ao encontrar grupos de municípios próximos e que carregam as mesmas características socioeconômicas analisadas a partir da visualização em um mapa.

Figura 2 - Análise da dependência espacial local (LISA) da pobreza em Minas Gerais, 2010

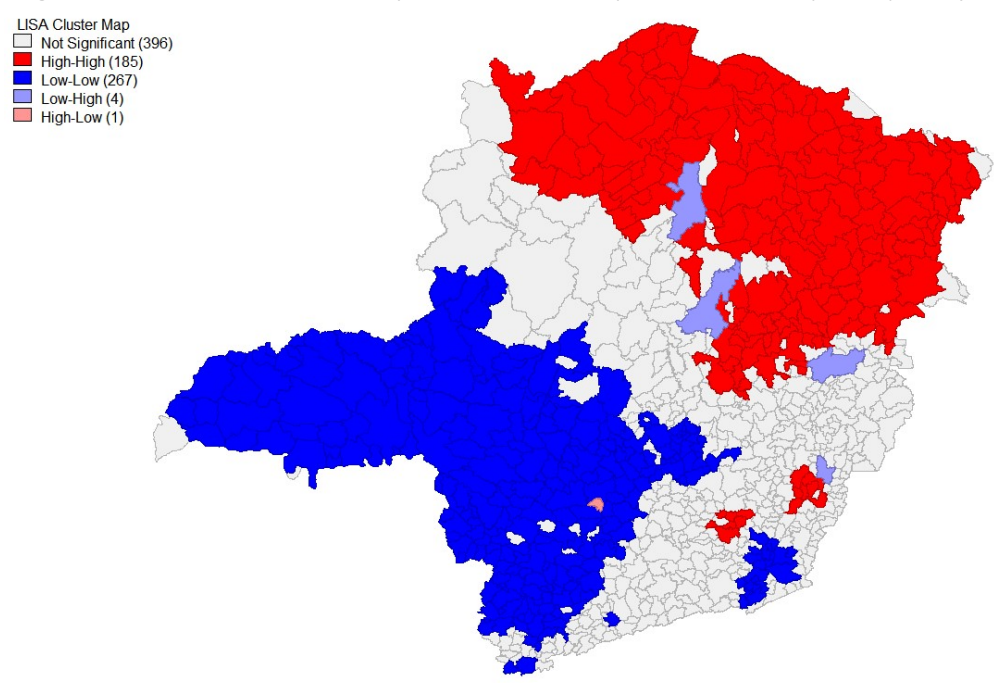

Fonte: Elaboração própria a partir de dados do Censo 2010 disponibilizados pelo IBGE.

Cabe destacar, primeiramente, que 457 observações são estatisticamente significantes a $5 \%$, sendo os municípios em cinza não estatisticamente significantes. Assim, a análise da figura 2 já indica a formação de clusters de pobreza. Isso porque, em vermelho, há a aglomeração de munícipios pobres. E em azul, há aglomeração de municípios ricos. Ou seja, na parte em vermelho, na região norte do Estado, há a formação de um cluster de pobreza. Os municípios em azul claro e vermelho claro representam os outliers, aqueles municípios cujo comportamento é diferente do de seus vizinhos. 
p. 49 - Análise da dimensão espacial da pobreza em Minas Gerais

Figura 3 - Análise da dependência espacial da renda média em Minas Gerais, 2010

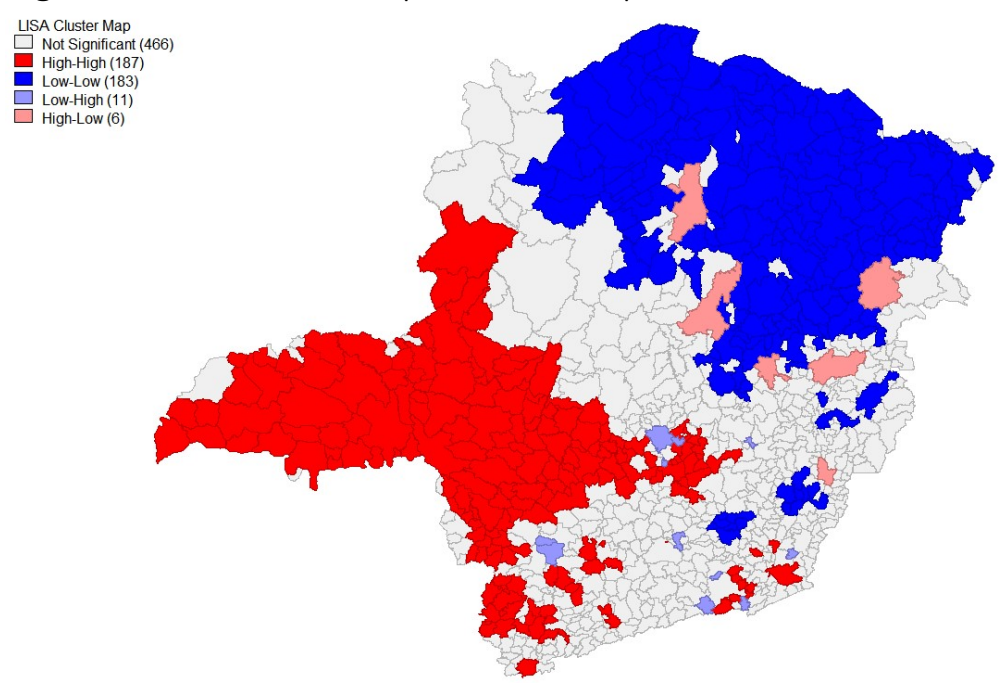

Fonte: Elaboração própria a partir de dados do Censo (2010) disponibilizados pelo IBGE.

Na figura 3, mantém-se a análise feita anteriormente. Em azul, há a aglomeração de municípios de com baixa renda média per capita e em vermelho, há a aglomeração de municípios com alta renda per capita. Há, nesse caso, a formação de um cluster de baixa renda na região norte de Minas. Depreende-se, portanto, que além das características específicas e internas aos municípios dessa região, o fato de estarem localizados onde estão impacta na sua renda média. Os municípios em vermelho e azul claro representam os outliers, municípios cujo comportamento é diferente do de seus vizinhos.

\subsubsection{Modelo econométrico}

i) Método dos mínimos quadrados

Logo, assim como foi definido anteriormente, é preciso inicialmente estimar o modelo desejado por meio do Método dos Mínimos Quadrados Ordinários (MQO).

Tabela 3 - Estimadores da regressão por MQO

\begin{tabular}{llll} 
Variável & Coeficiente & Desvio-padrão & p-valor \\
\hline Constante & 14,8231 & 1,5252 & 0,000 \\
Renda média & $-0,0674$ & 0,0014 & 0,000 \\
Urbanização & $-0,0747$ & 0,0105 & 0,000 \\
Gini & 78,751 & 2,9249 & 0,000 \\
$R^{2}$ & 0,8536 & & \\
Jarque-Bera & 0,001 & & \\
Breush-Pagan & 0,001 & \\
White & 0,001 & & \\
\hline
\end{tabular}

Fonte: Elaboração própria. 
A tabela 3 apresenta os resultados da regressão por MQO para o modelo em questão. Assim como era esperado, têm-se parâmetros positivos para o Índice de Gini e parâmetros negativos para as variáveis renda média e urbanização. Esse resultado indica que um aumento da renda média e da taxa de urbanização reduzem a porcentagem de pobres, ao passo que um aumento do índice de Gini, situação em que há um aumento da desigualdade, aumenta a porcentagem de pessoas pobres. Cabe ressaltar que todas as variáveis utilizadas são estatisticamente significantes.

O grau de ajuste desse modelo é $85 \%$, ou seja, variações na renda média, na taxa de urbanização e no Índice de Gini explicam $85 \%$ das variações na taxa de pobreza. Todavia, os testes de Jacque-Bera e White são estatisticamente significantes. Ou seja, essa é uma amostra que não está normalmente distribuída (Jacque-Bera) e esse é um modelo heterocedástico (White). As duas informações, a não normalidade da amostra e a heterocedasticidade, são condizentes com uma situação de dependência espacial.

\section{ii) Métodos econométricos espaciais}

Estimado o modelo por MQO, é possível avançar na análise da dependência espacial. Primeiro, deve-se calcular os testes dos Multiplicadores de Lagrange a fim de definir se existe dependência espacial e se todos os testes são significativos. Caso sejam, deve-se analisar qual deles é mais significativo para definir qual modelo utilizar.

Tabela 4 - Multiplicadores de Lagrange

\begin{tabular}{lll} 
& Valor & Prob. \\
\hline$M L \rho$ & 262,3 & 0,000 \\
$M L \lambda$ & 83,59 & 0,000 \\
$M L * \rho$ & 181,29 & 0,000 \\
$M L * \lambda$ & 2,58 & 0,108 \\
\hline
\end{tabular}

Percebe-se pela tabela 4 que os Multiplicadores de Lagrange são ambos significativos, o que confirma que MQO não é o modelo mais apropriado para as variáveis em questão. Cabe ressaltar que sendo os Multiplicadores de Lagrange positivos deve-se aceitar a hipótese alternativa de que há dependência espacial. Nesse sentido, é preciso definir qual dos dois modelos utilizar. Segundo Vieira (2009), o Multiplicador de Lagrange (robusto) mais significante determina o modelo a ser utilizado. Nesse sentido, sendo o método da defasagem robusta mais significante do que o do erro robusto, o modelo mais indicado é o modelo por defasagem espacial.

Portanto, o modelo a ser estimado é dado pela equação:

$$
\text { Pobreza }=\rho W_{1} \beta_{1}+\beta_{2} \text { Renda média }+\beta_{3} \text { Urbanização }+\beta_{4} \text { Gini }+\varepsilon
$$


p. 51 - Análise da dimensão espacial da pobreza em Minas Gerais

Tabela 5 - Resultados do Modelo de Defasagem Espacial

\begin{tabular}{llll} 
Variável & Coeficiente & Desvio-padrão & p-valor \\
\hline Constante & 11,5823 & 1,259 & 0,000 \\
Renda média & $-0,0418$ & 0,001 & 0,000 \\
Urbanização & $-0,0828$ & 0,008 & 0,000 \\
Gini & 47,53 & 2,803 & 0,000 \\
$W$ & 0,4298 & 0,0207 & 0,000 \\
pobreza & 0,9 & & \\
$R^{2}$ & 4672,89 & & \\
Critério de Akaibe & 4696,63 & & 0,001 \\
Critério de Schwarz & 823,98 & & 0,001 \\
Likehood Radio Test & 263,41 & & \\
Breush-Pagan & & & \\
\hline
\end{tabular}

Na tabela 5, que apresenta os resultados para a estimação do modelo por meio do Método da Defasagem Espacial, os dados encontrados repetem os sinais dos parâmetros encontrados no modelo estimado por MQO. Todavia, nesse modelo, há uma redução dos estimadores frente ao outro modelo, ou seja, o impacto das variáveis na determinação da pobreza diminui. Além disso, cabe destacar nesse modelo a presença da variável defasada da pobreza que é estatisticamente significante e apresenta um valor significativo e maior do que a das outras variáveis (considerando o aumento de 0,001 no índice de Gini, levaria a um aumento de 0,047 na taxa de pobreza, mantendo tudo mais constante). Ou seja, pode-se dizer que a defasagem espacial é importante para o entendimento do nível de pobreza de um dado município. Todavia, apesar do método econométrico espacial possibilitar uma melhor estimação do modelo, este continua sendo heterocesdástico, haja vista que o teste de Breush-Pagan é estatisticamente significante, e continua havendo autocorrelação espacial, haja vista que o teste "Likehood Radio Test" permanece significativo.

Com base nos resultados encontrados, pode-se dizer um município pobre impacta na pobreza de seus vizinhos. De forma que a pobreza na vizinhança é um fator mais importante para explicar a pobreza de um dado município do que o índice de Gini, o grau de urbanização e a renda média desse município.

\section{CONSIDERAÇÕES FINAIS}

A pobreza pode ser analisada por várias perspectivas distintas: por um viés unidimensional, em que o rendimento per capita é o principal fator para definir se uma pessoa é pobre ou não, quanto por um viés multidimensional, que considera tanto o aspecto da renda, mas também aspectos culturais e sociais como acesso a saneamento básico, a tratamento de água e a educação e até mesmo critérios imateriais, como o grau de inserção do indivíduo em uma dada sociedade. Assim, pode-se resumir o conceito de pobreza como sendo uma situação de carência generalizada. 
Nesse sentido, sabe-se que o Brasil é um país gigantesco e diverso, mas também marcado por intensas disparidades regionais. No que tange a pobreza não seria diferente. O país se divide em regiões ricas e regiões pobres. Historicamente, as regiões que se deram melhor nos ciclos agrícolas e industriais se desenvolveram mais frente as demais. Todavia, essa desigualdade não se restringe apenas as regiões brasileiras. Essa relação de desigualdade permanece quando se analisam os municípios de um mesmo estado, como é o caso de Minas Gerais.

Logo, é a partir dessa perspectiva que se fez necessário analisar, por meio da econometria espacial, a distribuição da pobreza nos municípios mineiros. Nesse trabalho, optou-se por investigar o comportamento de três variáveis frente a pobreza: índice de Gini, renda média e grau de urbanização. Por meio da análise exploratória dos dados (AEDE) e do cálculo do Índice de Moran foi possível confirmar a existência de dependência espacial. A partir de um Índice de Moran univariado positivo e maior que zero, foi possível comprovar que municípios pobres se associam a municípios pobres. Além disso, por meio dos mapas, foi possível visualizar a formação dos clusters de pobreza, ou seja, a aglomeração de municípios pobres no Norte de Minas Gerais e a aglomeração de municípios ricos no Sul de Minas.

Além disso, ao estimar o modelo de Defasagem espacial foi possível ratificar a situação de dependência espacial entre as variáveis e complementar as análises. A partir desse modelo, confirmou-se que um aumento do Índice de Gini impacta positivamente na taxa de pobreza e que aumentos no grau de urbanização e na renda média impactam negativamente na taxa de pobreza. Nesse modelo aparece também uma nova variável: a variável pobreza defasada. Essa variável tem efeito positivo sobre a taxa de pobreza, o que significa que estar próximo a um município pobre aumenta as chances de um município ser também pobre.

Portanto, partindo de conceituações teóricas sobre o que é pobreza e por uma breve análise da situação de pobreza no Brasil e em Minas Gerais, esse artigo teve como objetivo principal investigar a dimensão espacial da pobreza em Minas Gerais. A partir do cálculo do Índice de Moran foi possível atestar que as variáveis pobreza, renda média, grau de urbanização e Índice de Gini são espacialmente dependentes e por meio do modelo de Defasagens Espaciais comprovou-se que o nível de pobreza de um município impacta no nível de pobreza dos seus vizinhos.

Em razão do seguinte trabalho ter tido um escopo de análise reduzido, por considerar apenas Minas Gerais e ter considerado a pobreza pelo ponto de vista unidimensional, suas análises são insuficientes para uma interpretação completa do problema da pobreza espacial no Brasil. Todavia, esse estudo é suficiente para comprovar a dependência espacial na distribuição de municípios pobres, o que ratifica a importância de que as políticas de combate à pobreza considerem a distribuição espacial dos municípios e os clusters de pobreza que se formam. As estratégias de combate à pobreza só serão eficazes se o caráter regional passar a ter preponderâncias às que consideram os municípios analisados isoladamente. 
p. 53 - Análise da dimensão espacial da pobreza em Minas Gerais

\section{REFERÊNCIAS}

ALVES, Luiz Fernando; FONTES, Rosa. Desigualdades inter-regionais na distribuição de renda e na repartição da pobreza em minas gerais. Revista Econômica do Nordeste, Fortaleza, v. 32, n. 1, p.36-50, 2001.

AVILA, José Flávio; BAGOLIN, Izete Pengo. Pobreza no Rio Grande Sul: uma análise exploratória da sua distribuição espacial a partir de indicadores uni e multidimensionais. Estudo e Debate, Lajeado, v. 21, n. 2, p.25-47, 2014.

BARROS, Ricardo Paes de; HENRIQUES, Ricardo; MENDONÇA, Rosane. Desigualdade e pobreza no Brasil: retrato de uma estabilidade inaceitável. Revista Brasileira de Ciências Sociais, [s.I.], v. 15, n. 42, p.123-142, fev. 2000. FapUNIFESP (SciELO).

CAON, Ana Vitoria Rogério; MAGALHÃES, Maria Regina Alvares; MOREIRA, Mario Cesar Rocha. Situação da pobreza em Minas Gerais. Revista do Legislativo, Belo Horizonte, v. 44, p.22-42, 2012.

CHIARINI, Tulio. Análise espacial da pobreza municipal no Ceará, 1991-2000. Revista de Economia, [s.I.], v. 34, n. 2, p.69-93, 18 set. 2008. Universidade Federal do Paraná.

DE SOUZA VIEIRA, Rodrigo. A abordagem clássica de Econometria Espacial. Scielo Books, São Paulo, 2009.

FAHEL, Murilo Cassio Xavier; LEITE, Guilherme Paiva; TELES, Letícia Ribeiro. Pobreza Multidimensional no estado de Minas Gerais: uma mensuração para além da renda. Revista Brasileira de Monitoramento e Avaliação, [s.i.], v. 8, p.50-69, 2014.

FAHEL, Murilo; TELES, Letícia Ribeiro; CAMINHAS, Davy Alves. PARA ALÉM DA RENDA. Uma análise da pobreza multidimensional no Brasil. Revista Brasileira de Ciências Sociais, [s.I.], v. 31, n. 92, p.01-21, 31 out. 2016. FapUNIFESP (SciELO).

FARIAS, Hellen Nunes de; LEIVAS, Pedro Henrique; MENEZES, Gabrielito. ANÁLISE ESPACIAL DA POBREZA NOS MUNICÍPIOS GAÚCHOS. Revista Estudo \& Debate, [s.I.], v. 25, n. 2, p.91-110, 5 set. 2018. Editora Univates. http://dx.doi.org/10.22410/issn.1983036x.v25i2a2018.1620.

KAGEYAMA, Angela; HOFFMANN, Rodolfo. Pobreza no Brasil: Uma perspectiva multidimensional. Economia e Sociedade, Campinas, v. 15, n. 1, p.79-112, 2006.

PEREIRA, Claudinei Silva; HESPANHOL, Antonio Nivaldo. Região e regionalizações no Estado de Minas Gerais e suas vinculações com as políticas públicas. Revista Formação, Presidente Prudente, v. 1, p.42-70, 2015.

RACHED, Gabriel. Pobreza e aspectos estruturais da distribuição de renda no Brasil nas últimas décadas do século XX. In: CONFERÊNCIA NACIONAL DE POLÍTICAS PÚBLICAS CONTRA A POBREZA E A DESIGUALDADE, 2010, Natal. Anais: Natal: Ufrn, 2010. p. 1 - 19. SANTOS, Eli Izidro dos; CARVALHO, Ícaro Célio Santos de; BARRETO, Ricardo Candéa Sá. Pobreza multidimensional no estado da Bahia: uma análise espacial a partir dos censos de 2000 e 2010. Revista de Administração Pública, [s.l.], v. 51, n. 2, p.240-263, mar. 2017. FapUNIFESP (SCIELO).

SANTOS, Eli Izidro dos; CARVALHO, Ícaro Célio Santos de; BARRETO, Ricardo Candéa Sá. Pobreza multidimensional no estado da Bahia: uma análise espacial a partir dos censos de 2000 e 2010. Revista de Administração Pública, [s.I.], v. 51, n. 2, p.240-263, mar. 2017. FapUNIFESP (SciELO).

SANTOS, Gilmar Ribeiro dos; PALES, Raíssa Cota. Desenvolvimento Regional e Desigualdades Sociais entre as Macrorregiões de Planejamento de Minas Gerais. In: 
ENCONTRO ANUAL DA ANPOCS, 35., 2012, Montes Claros. Anais... . Monte Claros: Encontro Anual da Anpocs, 2012. p. 1 - 23.

SILVA, Alane Maria da; COSTA, Maria Bizerra da. Aspectos conceituais sobre pobreza: o Brasil sob o prisma de observação. In: JORNADA INTERNACIONAL POLITICAS PÚBLICAS., 2017, São Luís. Políticas públicas no Brasil: exploração e diagnóstico. São Luís': Atena, 2017. p. $72-82$.

SILVA, Leandro Nunes Soares da; BORGES, Murilo José; PARRÉ, José Luiz. Distribuição Espacial da Pobreza no Paraná. Revista de Economia, [s.I.], v. 39, n. 3, p.35-58, 31 dez. 2013. Universidade Federal do Paraná.

SILVA, Elydia; FONTES, Rosa; ALVES, Luiz Fernando. Crescimento e desigualdade de renda em Minas Gerais. Revista Econômica do Nordeste, v. 37, n. 1, p. 54-78, 2006.

SIMÃO, Rosycler Cristina Santos. Distribuição de renda e pobreza no estado de Minas Gerais. 2004. 129 f. Dissertação (Mestrado) - Curso de Economia Aplicada, Escola Superior de Agricultura Luiz de Queiroz, Piracicaba, 2004.

SOARES, Sergei Suarez Dillon. Metodologias Para Estabelecer a Linha de Pobreza: Objetivas, Subjetivas, Relativas e Multidimensionais. 1381. ed. Rio de Janeiro: Ipea, 2009. $53 \mathrm{p}$.

YASBEK, Maria Carmelita. Pobreza no Brasil contemporâneo e formas de seu enfrentamento. Revista de Políticas Públicas, São Luís, v. 9, n. 1, p.288-322, 2005. 